\title{
Endoscopic treatment of suprasellar cysts without hydrocephalus
}

\author{
Song-Bai Gui, MD, ${ }^{1}$ Sheng-Yuan Yu, MD, ${ }^{2}$ Lei Cao, MD, ${ }^{1}$ Ji-wei Bai, MD, ${ }^{1}$ Xin-Sheng Wang, MD, ${ }^{1}$ \\ Chu-Zhong Li, MD, ${ }^{2}$ and Ya-Zhuo Zhang, MD²
}

\begin{abstract}
1Department of Neurosurgery, Beijing Tiantan Hospital, Capital Medical University; and ²Beijing Neurosurgical Institute, Beijing, People's Republic of China
\end{abstract}

\begin{abstract}
OBJECTIVE At present, endoscopic treatment is advised as the first procedure in cases of suprasellar arachnoid cysts (SSCS) with hydrocephalus. However, the appropriate therapy for SSCs without hydrocephalus has not been fully determined yet because such cases are very rare and because it is usually difficult to perform the neuroendoscopic procedure in patients without ventriculomegaly given difficulties with ventricular cannulation and the narrow foramen of Monro. The purpose of this study was to find out the value of navigation-guided neuroendoscopic ventriculocystocisternostomy (VCC) for SSCs without lateral ventriculomegaly.

METHODS Five consecutive patients with SSC without hydrocephalus were surgically treated using endoscopic fenestration (VCC) guided by navigation between March 2014 and November 2015. The surgical technique, success rate, and patient outcomes were assessed and compared with those from hydrocephalic patients managed in a similar fashion.
\end{abstract}

RESULTS The small ventricles were successfully cannulated using navigational tracking, and the VCC was accomplished in all patients. There were no operative complications related to the endoscopic procedure. In all patients the SSC decreased in size and symptoms improved postoperatively (mean follow-up 10.4 months).

CONCLUSIONS Endoscopic VCC can be performed as an effective, safe, and simple treatment option by using intraoperative image-based neuronavigation in SSC patients without hydrocephalus. The image-guided neuroendoscopic procedure improved the accuracy of the endoscopic approach and minimized brain trauma. The absence of hydrocephalus in patients with SSC may not be a contraindication to endoscopic treatment.

http://thejns.org/doi/abs/10.3171/2016.4.PEDS15695

KEY WORDS arachnoid cyst; suprasellar; endoscopic treatment; neuronavigation; ventriculocystocisternostomy; hydrocephalus

0 UPRASELLAR cysts (SSCs) are benign developmental collections of CSF and constitute approximately 9\% of all arachnoid cysts. ${ }^{22}$ Their presence in utero and their high prevalence in children who have no history of trauma support the assumption that they are congenital. ${ }^{8,19,20}$

For patients with SSC who have hydrocephalus, many authors advise endoscopic surgery as the primary treatment. ${ }^{1,3-5,7,9,17,27}$ Until now, reported SSCs have numbered about 300 cases. ${ }^{1,3-5,7,9,17,27}$ But only 3 cases of SSC without hydrocephalus have been documented in the literature (Table 1). ${ }^{1,9,17}$ One among those cases had no symptoms and did not need an operation. Another case was treated using open fenestration. And in the third case, the author did not mention whether the operation was performed. The small number of cases has prevented studies of SSCs without hydrocephalus, which makes the choice of treatment less clear.

Logically, one would expect that in the absence of hydrocephalus, the success of endoscopic ventricular access and cyst fenestration would be reduced because of the difficulty with ventricular cannulation and intraventricular navigation. Further, the morbidity of such procedures may also be influenced by the degree of ventriculomegaly. However, with the recent development of neuroendoscopy coupled with a navigational system, a small ventricle is no

ABBREVIATIONS CSF = cerebrospinal fluid; ICP = intracranial pressure; SSC = suprasellar cyst; VC = ventriculocystostomy; VCC = ventriculocystocisternostomy. SUBMITTED November 27, 2015. ACCEPTED April 5, 2016.

INCLUDE WHEN CITING Published online June 17, 2016; DOI: 10.3171/2016.4.PEDS15695. 
TABLE 1. The SSCs without hydrocephalus reported in the literature

\begin{tabular}{lccccc}
\hline \multicolumn{1}{c}{ Authors \& Year } & $\begin{array}{c}\text { No. of } \\
\text { Patients }\end{array}$ & Clinical Manifestations & Surgical Procedures & Outcome & $\begin{array}{c}\text { Mean FU Time } \\
\text { (mos) }\end{array}$ \\
\hline Crimmins et al., 2006 & 1 & Not mentioned & Open fenestration & Not mentioned & Not mentioned \\
\hline Gui et al., 2011 & 1 & Asymptomatic & Conservatively management & Asymptomatic & 76 \\
\hline Ozek \& Urgun, 2013 & 1 & Not mentioned & Not mentioned & Not mentioned & Not mentioned \\
\hline Current series & 5 & $*$ & Endoscopic fenestration & $100 \%$ improved & 10 \\
\hline FU = follow-up. & & & & & \\
* See Table 2. & & & & &
\end{tabular}

longer a contraindication to intraventricular endoscopic surgery. ${ }^{12,15,24,26}$ To describe the usefulness and therapeutic effect of endoscopic surgery guided by neuronavigation, we present our experience with 5 SSCs without hydrocephalus that were treated with endoscopic VCC at our hospital.

\section{Methods \\ Study Population}

The hospital records of 5 SSC patients who had been treated in our department were reviewed (Table 2). Magnetic resonance imaging was performed for all patients before the operation. Computed tomography scans for all the patients were obtained on the day of surgery. Magnetic resonance imaging was also performed in the 1st postoperative week and at 3 and 12 months after surgery during the follow-up period. The MRI features of the 5 cases before operation included 1) cystic masses occupying the suprasellar cistern with an MRI signal intensity similar to CSF on all sequences; 2) marked dilation of the third ventricles on axial imaging, though lateral ventricles were not dilated; and 3) sagittal T1-weighted MR images of the SSCs demonstrated the 3 diagnostic features of displacement of the pituitary stalk and optic chiasm upwards and forward, displacement of the mammillary bodies upwards and backward, and effacement of the ventral pons (Figs. $1-5)$.

\section{Operative Technique}

All surgical procedures were performed with the patient under general anesthesia, who was positioned in the neutral supine position with the head elevated about $20^{\circ}$. We used a rigid endoscope guided by an electromagnetic neuronavigational system (Medtronic S7). After image acquisition, facial surface match registration was performed. After a 5-cm arc scalp incision was made, a $10-\mathrm{mm}$ bur hole about $3 \mathrm{~cm}$ lateral to the midline and $1 \mathrm{~cm}$ anterior to the coronal suture was created. Once the dura mater was opened, a $0^{\circ}$ straightforward rigid neuroendoscope was used to cannulate the lateral ventricle guided by neuronavigation. In all procedures, the navigational system guided the surgeons precisely into the narrow ventricles. After identifying the main anatomical landmarks, including the choroid plexus, fornix, and veins, the endoscope was advanced to the foramen of Monro (Figs. 1A, 2A and B, 3A, $4 \mathrm{~A}$, and $5 \mathrm{~A}$ ). Continuous irrigation was then used to inflate the narrow foramen of Monro. A constant purge was used throughout the procedure to avoid over-insufflating the ventricular system and elevating the intracranial pressure (ICP) by maintaining patency of a portal separate from the working channel. After the endoscope moved through or near the foramen of Monro, the apical dome of the SCC could be seen (Figs. 1B-D, 2A and B, and 3B). First, small blood vessels on the cyst wall were obliterated using a bipolar coagulator. Then, the cyst wall was resected as much as possible by using scissors to make a large fenestration in its apical membrane (Figs. 1E, 2C, 3C, 4B, and 5B). This completed the ventriculocystomy procedure.

To perform the cystocisternostomy, the endoscope was advanced into the cyst, allowing visual inspection of the displaced cisternal contents (Figs. 2D and E, 3D, and 5C). After inspection, the endoscope was further advanced to the basal cyst membrane, where a cyst-basal cistern fenestration was performed anterior to the basilar artery to complete the VCC. A slit valve-like structure formed by an arachnoid membrane around the basilar artery was noticed in $2(40 \%)$ of 5 patients at the basal cyst membrane (Figs. 1F and 3E). The slit valve opened and closed synchronously with arterial pulsation. For these cases, the slit valve-like arachnoid membrane around the basilar artery was first widened from the slit valve into a fenestration by using scissors to make a cystocisternostomy, which would allow communication between the cyst and basal cistern,

TABLE 2. Clinical characteristics of 5 cases of SSCs without hydrocephalus treated with a navigation-guided endoscopic procedure

\begin{tabular}{|c|c|c|c|c|c|}
\hline Case No. & Sex/Age & Clinical Manifestations & $\begin{array}{l}\text { Endoscopic } \\
\text { Procedure }\end{array}$ & FU (mos) & Outcome \\
\hline 1 & $M / 5 \mathrm{yrs}$ & Headache for half a yr \& gait ataxia for 1 mo & VCC & 8 & Successful \\
\hline 2 & $\mathrm{M} / 12 \mathrm{mos}$ & Seizures 3 times a mo & VCC & 10 & Successful \\
\hline 3 & $\mathrm{M} / 5 \mathrm{yrs}$ & Dizziness for half a yr \& blurred vision for $1 \mathrm{mo}$ & VCC & 13 & Successful \\
\hline 4 & $\mathrm{~F} / 5 \mathrm{yrs}$ & Gait ataxia for 2 mos \& weakness of the It upper limbs for 1 mo & VCC & 18 & Successful \\
\hline 5 & $\mathrm{M} / 19 \mathrm{mos}$ & Progressive gait ataxia for 2 mos & VCC & 3 & Successful \\
\hline
\end{tabular}



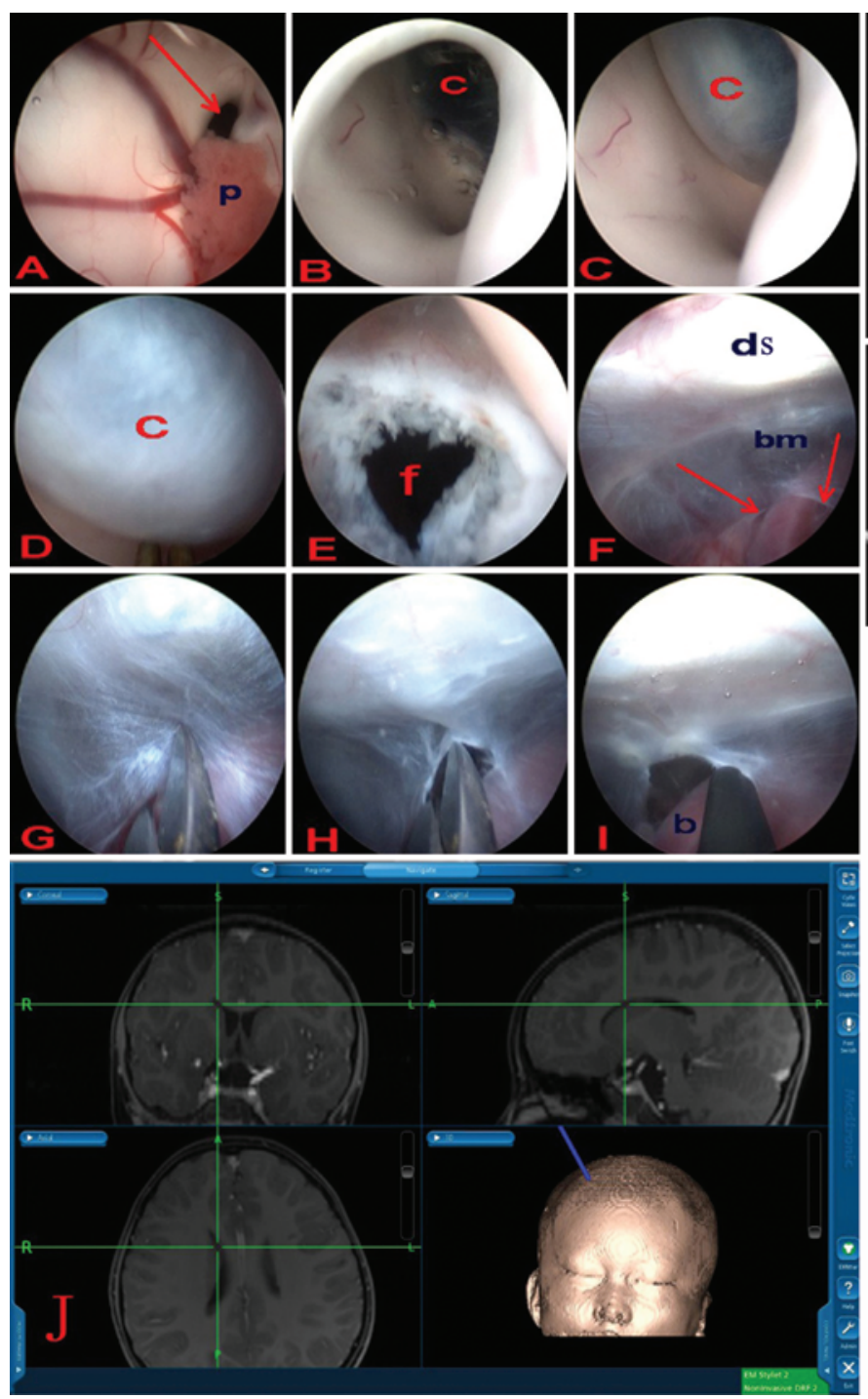

and then the fenestration was further widened by shrinking the membrane around the fenestration by using bipolar coagulation (Figs. $1 \mathrm{G}-\mathrm{I}$ and $3 \mathrm{~F}$ and $\mathrm{G}$ ). If there was no slit valve-like mechanism, one or multiple fenestrations were made in avascular portions of the basal cyst membrane by using scissors between the cranial nerves exiting the brainstem anterior to the basilar artery (Figs. 2F, 4C and $\mathrm{D}$, and 5D). The fenestration should be as large as possible. Compared with their use in the ventriculomegaly in SCCs with hydrocephalus (Fig. 6), movement of the endoscope and surgical instruments should be smaller and gentler because of the narrow space and small foramen of Monro in cases of SCCs without hydrocephalus.

\section{Results}

The patient follow-up ranged from 3 to 18 months. There were no perioperative or postoperative complications. When the signs and symptoms improved, postoperative MRI demonstrated that the cysts had shrunk, the optic apparatus and mammillary bodies reoriented to a more horizontal position, and pontine deformation improved,
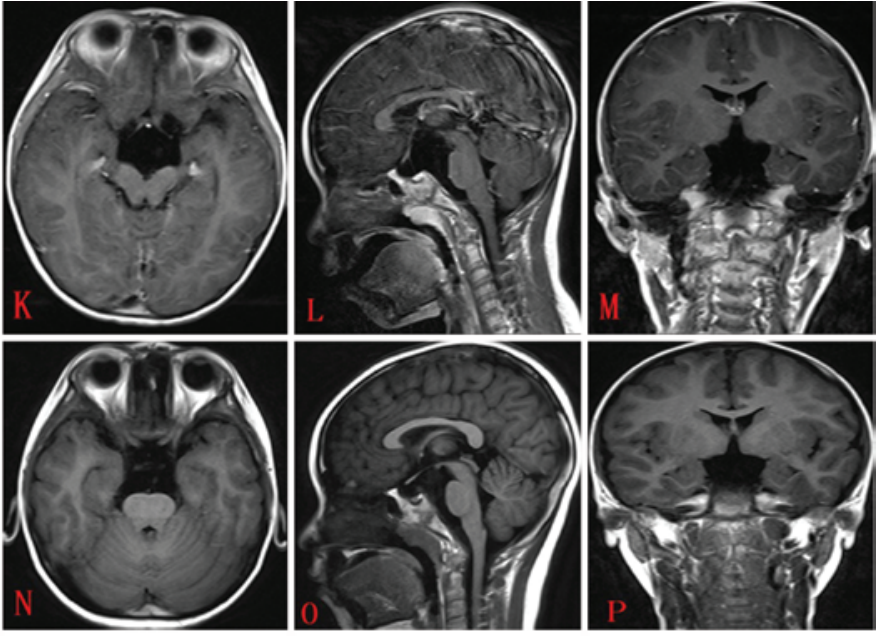

FIG. 1. Case 1. Intraoperative neuroendoscopic views. A: Arrow indicates the narrow foramen of Monro. B-D: The apical dome of an SSC is more clearly seen after continuous irrigation to inflate the narrow foramen of Monro. E: Fenestration of the apical cyst membrane. F: Arrows indicate the valve-like structure of the basal cyst membrane around the basilar artery. G-I: Widening of the valve into fenestration is done using scissors and bipolar coagulation. J: The endoscope enters the lateral ventricle guided by neuronavigation. K-M: Preoperative MR images. N-P: Postoperative MR images showing an apparent decrease in the size of the cyst. $b=$ basilar artery; $b m=$ basal cyst membrane; $c=$ cyst $; d s=$ dorsum sellae; $f=$ fenestration; $p=$ plexus choroideus. Figure is available in color online only.

the endoscopic procedure was considered to be successful. None of the patients had symptoms of hypothalamic-pituitary functional disorder before or after surgery. Neither did laboratory tests find any abnormity of hypothalamicpituitary function before or after surgery. In the follow-up period, the symptoms of all 5 patients disappeared and the growth and development of the children were normal. The follow-up MRI showed a significant reduction of the cyst size and the mass effect in all cases (Figs. 1-5).

\section{Discussion}

In our previous study, ${ }^{9}$ we found that most patients with SSCs at diagnosis are younger than 5 years old and that different age groups have different main clinical presentations. In infants, the main presenting clinical symptoms were macrocrania and motor deficits. In children and adolescents, the main presenting symptoms were elevated ICP, endocrine dysfunction, and reduced visual field or acuity. In adults, the main presenting symptom was elevated ICP. These age-related findings should be useful in the clinical setting for the diagnosis of SSCs. 


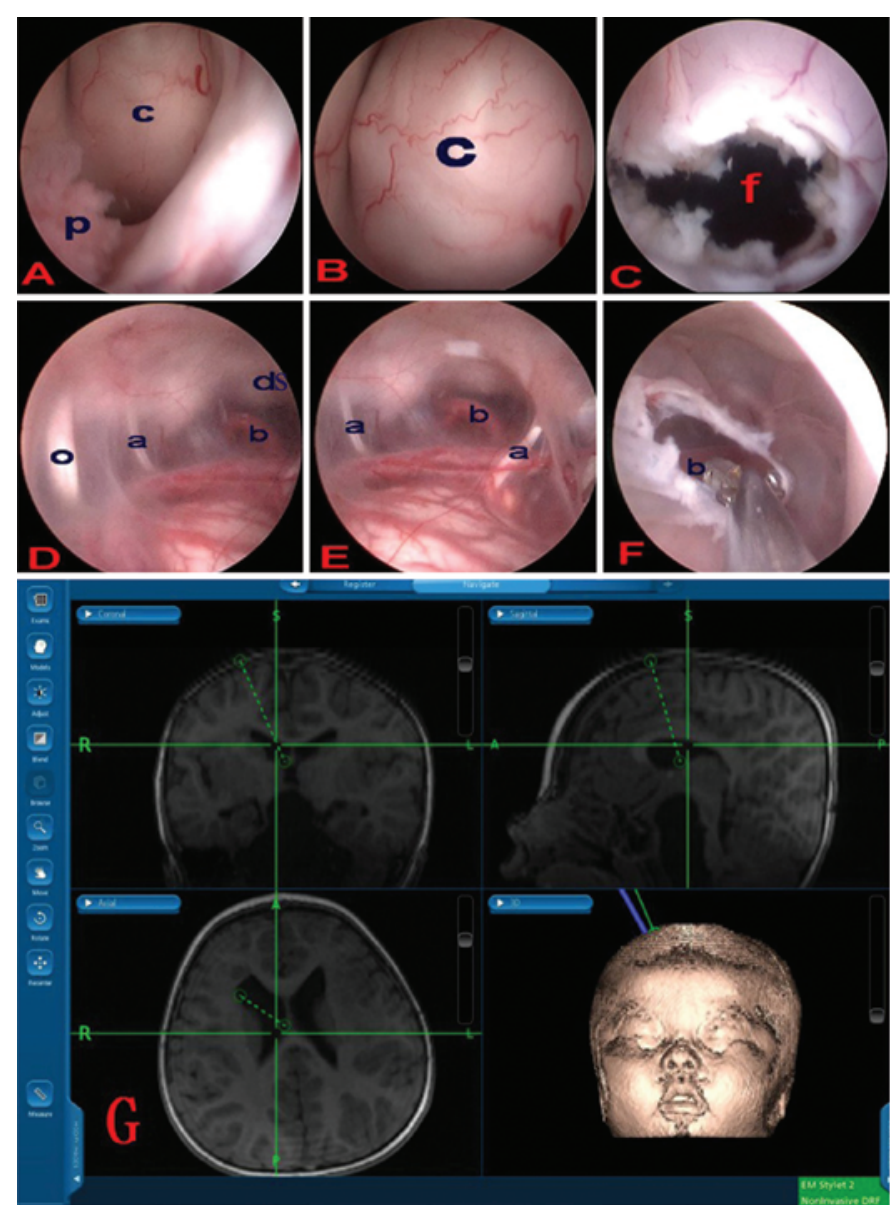

\section{Surgical Indications}

There is controversy about whether large but asymptomatic SSCs require surgery and which symptoms indicate that surgery is needed.

With regard to asymptomatic SSCs, regardless of their size, if they do not evolve, they do not need treatment. We found one case of SSC that spontaneously disappeared during follow-up, and other authors have also reported that SSCs may disappear spontaneously. ${ }^{14,18}$ Most of the cysts found during the prenatal period decreased in size, disappeared completely, or stabilized without associated clinical deficits during follow-up. ${ }^{1,8}$ Therefore, a conservative approach should be chosen if a child with a cyst has no symptoms, is neurologically intact, and undergoes close clinical and radiological observation. ${ }^{1,10,23}$ Surgery is indicated by progressive enlargement of the cyst even if a patient is asymptomatic.

With regard to symptomatic SSCs, in our previous series, ${ }^{9}$ symptoms of elevated ICP, motor deficits, head bobbing, and reduced visual field or acuity all improved in patients who had undergone surgery, which was successful, although endocrine disorders and gaze disturbance never resolved. In the present study, the symptoms (including elevated ICP, motor deficits, reduced visual acuity, and seizures) in all 5 patients also disappeared during the follow-up period. Our finding that gaze disturbance did not regress following treatment is consistent with findings
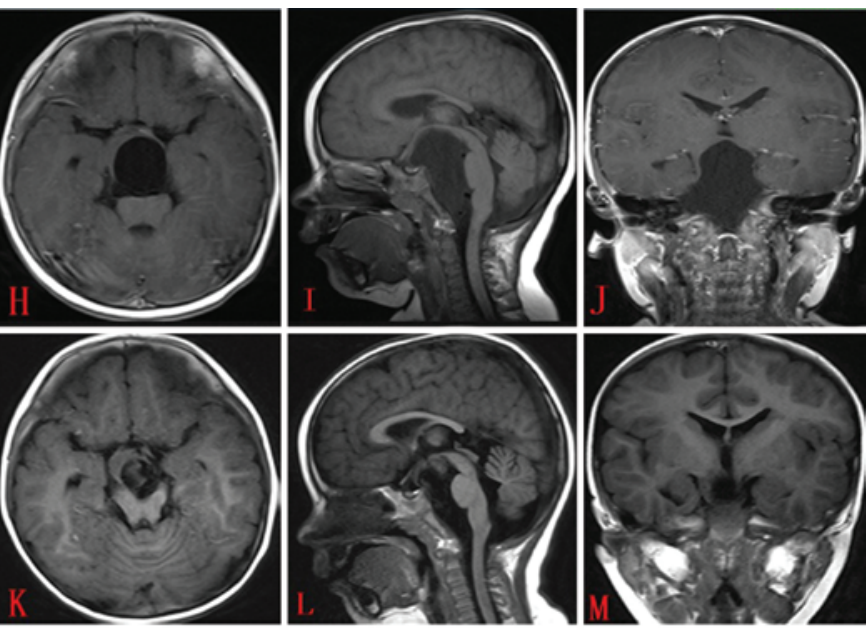

FIG. 2. Case 2. Intraoperative neuroendoscopic views. A and B: The apical dome of the SCC is seen more clearly after continuous irrigation to inflate the narrow foramen of Monro. C: Fenestration of the apical cyst membrane. D and E: Anatomical landmarks seen after the endoscope is advanced into the cyst. F: Fenestration of the basal cyst membrane is made in avascular portions of the basal cyst membrane between abducens nerves exiting the brainstem anterior to the basilar artery. G: The endoscope enters the lateral ventricle guided by neuronavigation. H-J: Preoperative MR images. K-M: Postoperative MR images showing an apparent decrease in the size of the cyst. $a=a b-$ ducens nerve; $0=$ oculomotor nerve. Figure is available in color online only.

by Erşahin et al., who found that endoscopic treatment of SCCs failed to improve bilateral sixth nerve palsy in one patient. ${ }^{5}$ Five patients in our previous study had new endocrine dysfunction during postoperative follow-up despite successful surgery. This observation has also been reported by other authors. ${ }^{1,23}$ Head bobbing also improved in all $6(100 \%)$ affected patients after surgery in our previous study. ${ }^{9}$ The other 3 cases that have been reported in the literature on patients with bobble-head syndrome, who have been successfully treated with endoscopic surgery for SCCs, provided additional evidence that head bobbing is an indication for surgery. ${ }^{6,11}$ In addition, it is a common observation that behavioral difficulties and mental retardation never regress postoperatively. ${ }^{1}$ Therefore, we argue that surgical indications should include signs of elevated ICP (including increased head circumference), motor deficits, head bobbing, and reduced visual field or acuity. Contraindications to surgery include isolated endocrine dysfunction, behavioral difficulties, mental retardation, or gaze disturbance.

\section{Choice of Surgical Procedure}

Suprasellar cysts can be divided into 2 types: with hydrocephalus or without hydrocephalus. It is very rare to see a patient with an SCC who does not have hydrocephalus.

The therapeutic goals in cases of SSCs with symptoms 

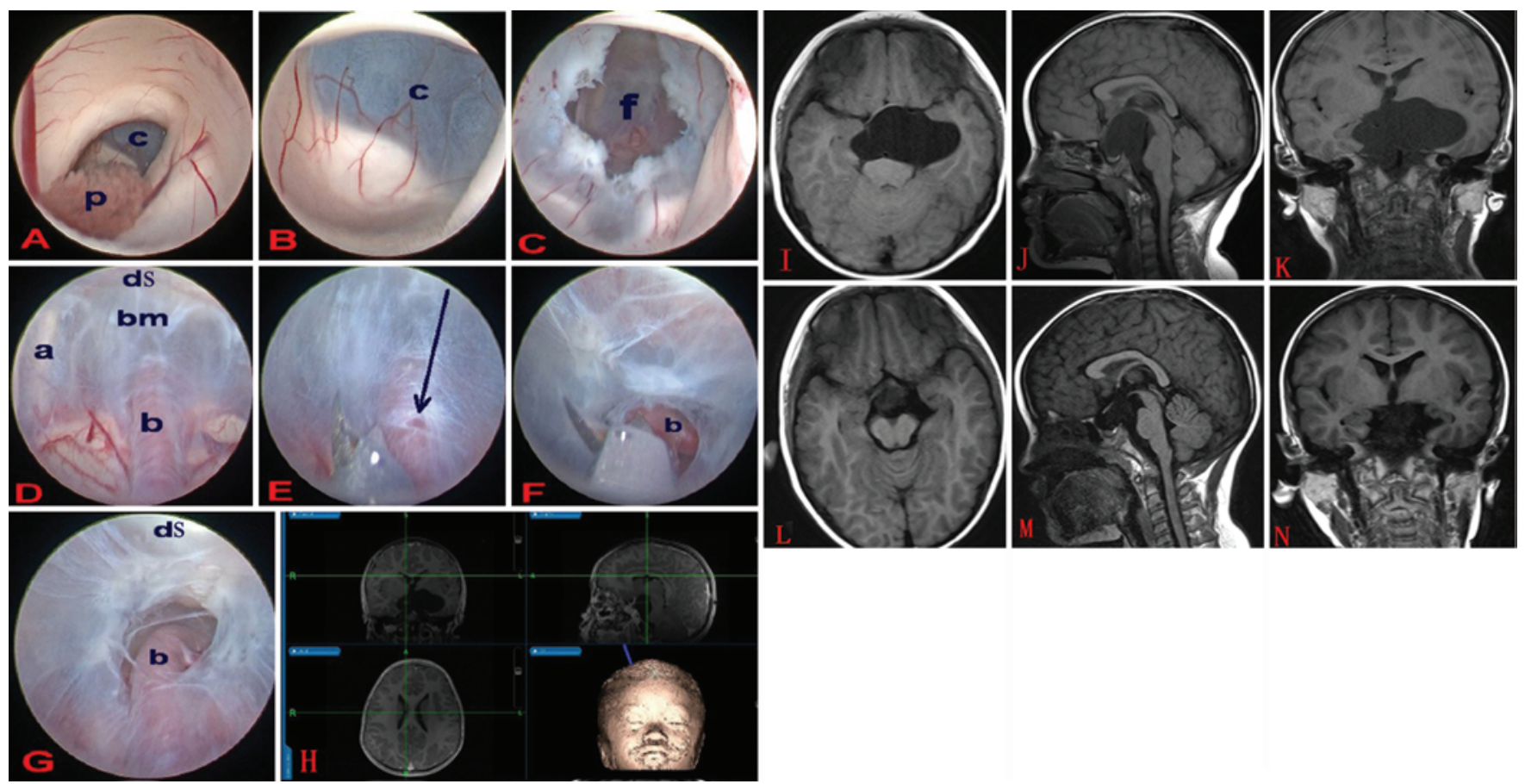

FIG. 3. Case 3. Intraoperative neuroendoscopic views. A: The narrow foramen of Monro. B: The apical dome of the SCC is seen more clearly after continuous irrigation to inflate the narrow foramen of Monro. C: Fenestration of the apical cyst membrane. $\mathrm{D}$ : Anatomical landmarks seen after the endoscope is advanced into the cyst. E: Arrow indicates the valve-like structure of the basal cyst membrane around the basilar artery. F and G: Widening of the valve into fenestration is done using scissors and bipolar coagulation. $\mathrm{H}$ : The endoscope enters the lateral ventricle guided by neuronavigation. I-K: Preoperative MR images. $\mathrm{L}-\mathrm{N}$ : Postoperative MR images showing an apparent decrease in the size of the cyst. Figure is available in color online only.
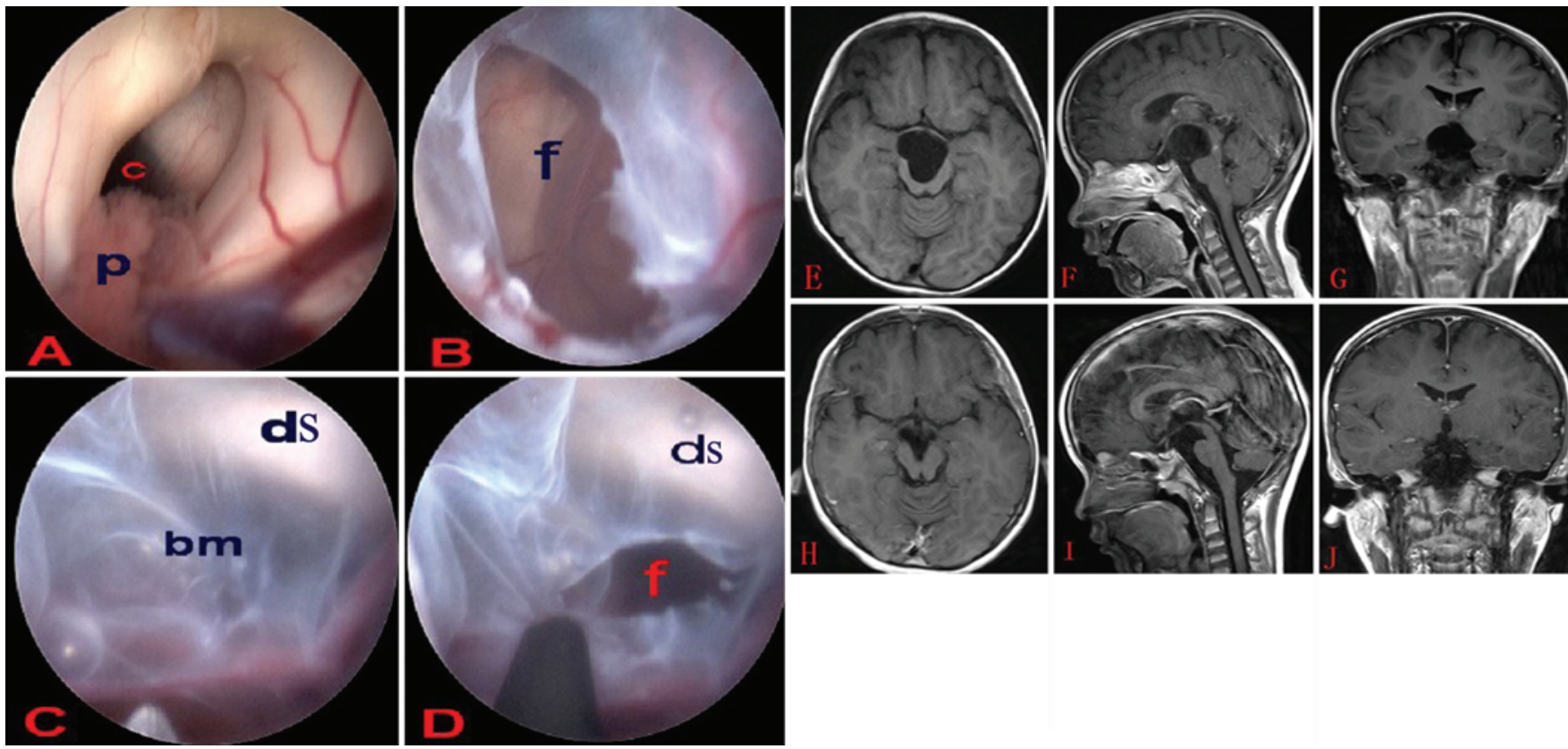

FIG. 4. Case 4. Intraoperative neuroendoscopic views. A: The narrow foramen of Monro. B: Fenestration of the apical cyst membrane. C: The basal cyst membrane. D: Fenestration of the basal cyst membrane. E-G: Preoperative MR images. H-J: Postoperative MR images showing that the cyst completely disappeared. Figure is available in color online only. 

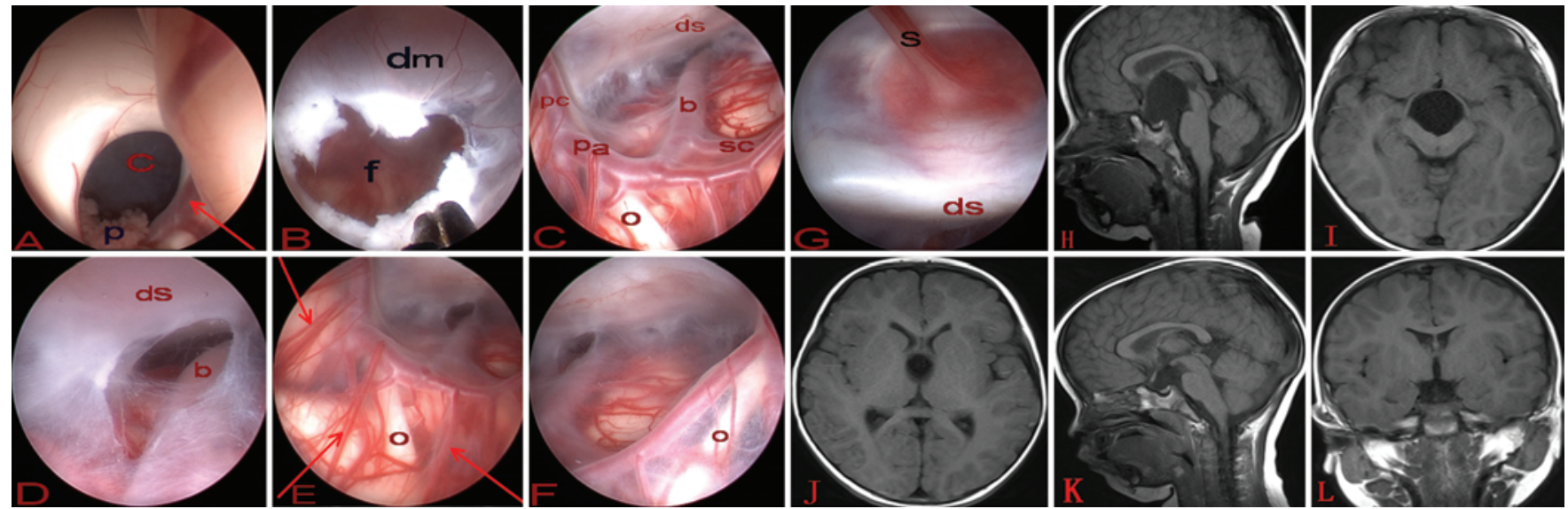

FIG. 5. Case 5. Intraoperative neuroendoscopic views. A: The narrow foramen of Monro. Arrow indicates vena thalamostriate. B: Fenestration of the apical cyst membrane. C: Anatomical landmarks seen after the endoscope is advanced into the cyst. D: Fenestration of the basal cyst membrane. E: Arrows indicate supplying vessels for the brainstem, which are branches of the posterior cerebral and posterior communicating arteries. F: The right oculomotor nerve. G: Pituitary stalk. H-J: Preoperative MR images. K and L: Postoperative MR images showing an apparent decrease in the size of the cyst. dm = apical dome of the $\mathrm{SCC} ; \mathrm{pa}=$ posterior cerebral artery; $\mathrm{pc}=$ posterior communicating artery; $\mathrm{s}=$ pituitary stalk; $\mathrm{sc}=$ superior cerebellar artery. Figure is available in color online only.

are to remove the mass effect from these cysts by resection, fenestration, or shunting of the cyst and to relieve the hydrocephalus. A direct approach to the cyst for microsurgical excision or fenestration is rather invasive because of the deep location of these cysts. ${ }^{13,16,21,25}$ The common problems with any shunting procedure, such as shunt malfunction, infection, and shunt dependency, are also well known. Moreover, the success rate of the ventriculoperitoneal shunt as a definitive treatment for SSCs is reported to be only $10 \% .^{16}$
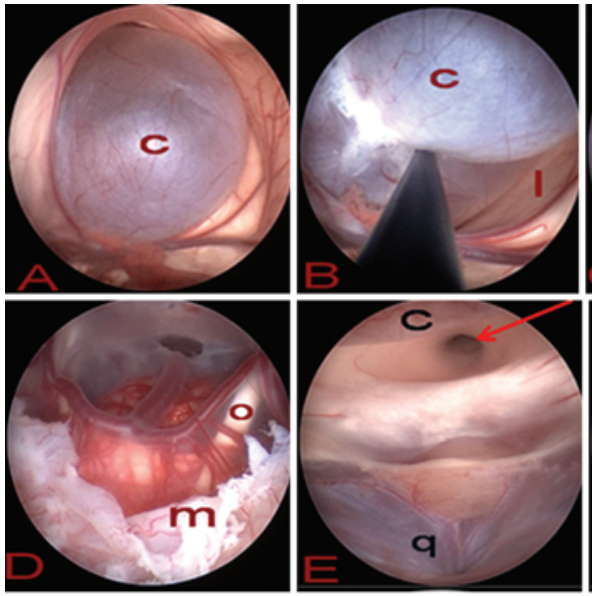
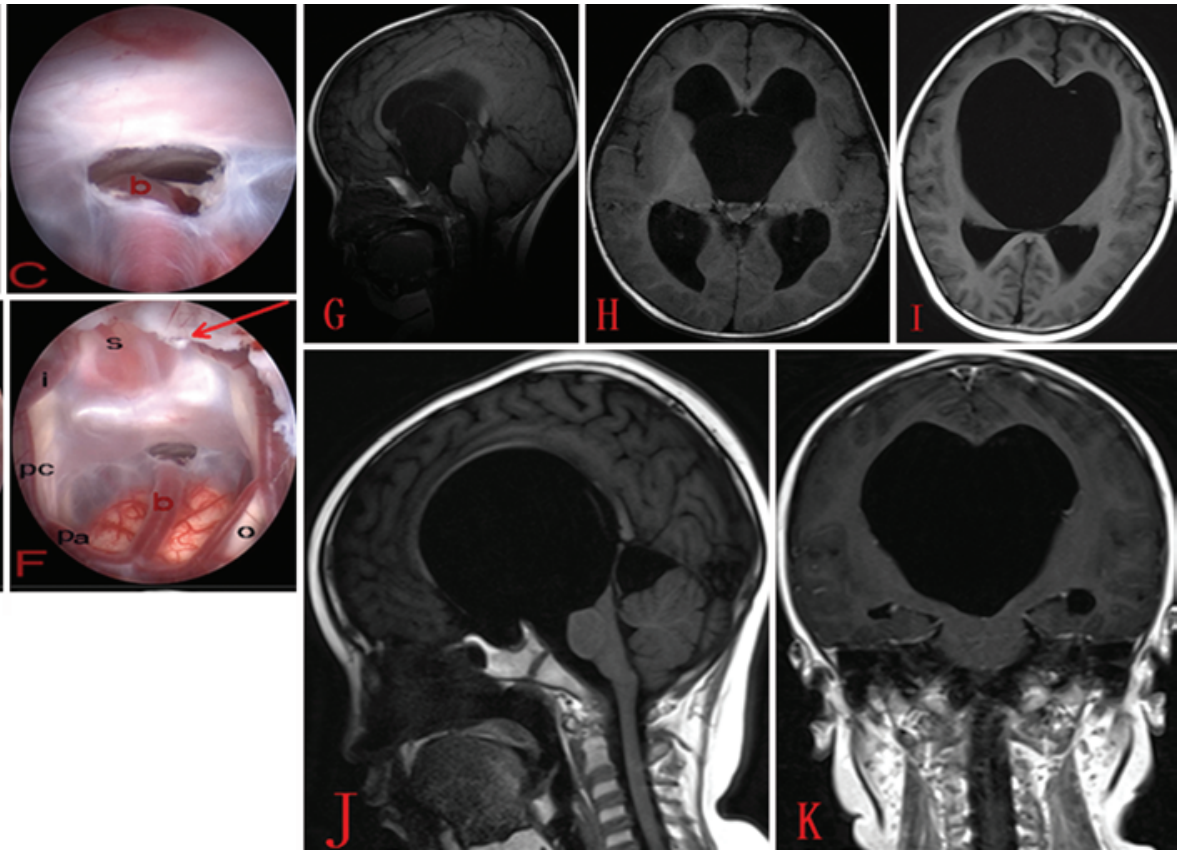

FIG. 6. Intraoperative neuroendoscopic views of SCC with hydrocephalus. A: The cyst intrudes into the lateral ventricle through the foramen of Monro. B: The cyst wall was shrunk. C: Fenestration of the basal cyst membrane. D: Fenestrations of the apical cyst membrane and basal cyst membrane. E: When the endoscope moved to the posterior third ventricle, the aqueduct of the midbrain and the anterior wall of the quadrigeminal cistern can be seen. Arrow indicates the aqueduct of midbrain. F: Endoscopic view of the circle of Willis through fenestration of the apical cyst membrane showing the internal carotid arteries, posterior cerebral arteries, posterior communicating arteries, basilar artery, oculomotor nerve, pituitary stalk, and dorsum sellae. Arrow indicates the margin of the apical dome fenestration. G-I: Preoperative MR images of SCC with hydrocephalus showing marked dilation of both third and lateral ventricles. $\mathrm{J}$ and $\mathrm{K}$ : Preoperative MR images of a very huge SCC with hydrocephalus showing that the cyst almost occupies all of the lateral ventricle. $\mathrm{i}=$ (in B) internal carotid artery; I = (in F) lateral wall of the third ventricle; $m=$ margin of the apical dome fenestration; $q=$ quadrigeminal cistern. Figure is available in color online only. 
Recently, advances in endoscopy have raised endoscopic fenestration to the initial surgical procedure in the management of SSCs with hydrocephalus at the present time, and the procedure has been demonstrated to be safe and effective. $1,5,7,9,25$ However, endoscopic surgery for patients without hydrocephalus is usually avoided because of the purported difficulty with ventricular cannulation and intraventricular navigation. Crimmins et al. believe that with the advances in microsurgical techniques, open marsupialization of the cyst into the basal cisterns is a more effective solution that should be preferred to shunt insertion and endoscopic treatment for the patients without hydrocephalus. ${ }^{1}$ In the present series, we found that endoscopic surgery guided by neuronavigation in the 5 SSC patients without hydrocephalus was effective and safe. Given the current results and our previous experience with the endoscopic treatment of SCCs with hydrocephalus, ${ }^{9}$ we think that endoscopic fenestration should be the first choice for the SSC patients without hydrocephalus.

There are presently 3 types of endoscopic surgical procedures for the treatment of SCCs: 1) ventriculocystostomy (VC), whose goal is to establish communication between the cyst cavity and the ventricles; 2) VCC, whose goal is to open the cyst into both the ventricles and the cisterns; and 3) VC followed by enough coagulation (shrinkage) of the cysts. ${ }^{2}$ We chose VCC because it was more frequently effective than VC. $1,7,9$

\section{Endoscopic Techniques}

Usually, more anatomical structures can be seen and the endoscopic procedures are more easy to perform in cases of SCCs with hydrocephalus because the space is big enough for movement of the endoscope and instruments (Fig. 6). Compared with conditions in ventriculomegaly in SCCs with hydrocephalus, the narrow space and small foramen of Monro in cases of SCCs without hydrocephalus limit movement and operative procedures of the rigid neuroendoscopy after the endoscope gains access to the ventricle; therefore, movement of the endoscope and surgical instruments should be smaller and gentler to avoid contusion of surrounding structures, such as the foramen of Monro and the wall of the ventricles, and continuous irrigation is often needed to inflate the narrow foramen of Monro for the endoscope to access the third ventricle. We fenestrate the apical dome of the SCC by resecting the freefloating wall of the cyst in the third ventricle with scissors and never dissect any cyst wall attached to the wall of the third ventricle. The free-floating cyst wall in the ventricle is large enough to fenestrate the apical dome of the SCC. The use of bipolar coagulation should be avoided on the basal membrane close to the abducens nerves when performing the fenestration on the basal cyst wall.

A limitation of this study is its short follow-up time. A long-term follow-up is needed to better assess the functionality of the endoscopic procedures in the treatment of SCCs without hydrocephalus.

\section{Conclusions}

The absence of hydrocephalus in patients with SCCs may not serve as a contraindication to endoscopic treatment. Endoscopic VCC guided by neuronavigation can also be effective and safe and should be considered as the first surgical procedure in SSC patients without hydrocephalus.

\section{References}

1. Crimmins DW, Pierre-Kahn A, Sainte-Rose C, Zerah M: Treatment of suprasellar cysts and patient outcome. J Neurosurg 105 (2 Suppl):107-114, 2006

2. Decq P, Brugieres P, Le Guerinel C, Djindjian M, Keravel Y, Nguyen JP: Percutaneous endoscopic treatment of suprasellar arachnoid cysts: ventriculocystostomy or ventriculocystocisternostomy? Technical note. J Neurosurg 84:696-701, 1996

3. Dodd RL, Barnes PD, Huhn SL: Spontaneous resolution of a prepontine arachnoid cyst. Case report and review of the literature. Pediatr Neurosurg 37:152-157, 2002

4. El-Ghandour NM: Endoscopic treatment of suprasellar arachnoid cysts in children. J Neurosurg Pediatr 8:6-14, 2011

5. Erşahin Y, Kesikçi H, Rüksen M, Aydin C, Mutluer S: Endoscopic treatment of suprasellar arachnoid cysts. Childs Nerv Syst 24:1013-1020, 2008

6. Fioravanti A, Godano U, Consales A, Mascari C, Calbucci F: Bobble-head doll syndrome due to a suprasellar arachnoid cyst: endoscopic treatment in two cases. Childs Nerv Syst 20:770-773, 2004

7. Gangemi M, Colella G, Magro F, Maiuri F: Suprasellar arachnoid cysts: endoscopy versus microsurgical cyst excision and shunting. Br J Neurosurg 21:276-280, 2007

8. Golash A, Mitchell G, Mallucci C, May P, Pilling D: Prenatal diagnosis of suprasellar arachnoid cyst and postnatal endoscopic treatment. Childs Nerv Syst 17:739-742, 2001

9. Gui SB, Wang XS, Zong XY, Zhang YZ, Li CZ: Suprasellar cysts: clinical presentation, surgical indications, and optimal surgical treatment. BMC Neurol 11:52, 2011

10. Hagebeuk EE, Kloet A, Grotenhuis JA, Peeters EA: Bobblehead doll syndrome successfully treated with an endoscopic ventriculocystocisternostomy. Case report and review of the literature. J Neurosurg 103 (3 Suppl):253-259, 2005

11. Hoffman HJ, Hendrick EB, Humphreys RP, Armstrong EA: Investigation and management of suprasellar arachnoid cysts. J Neurosurg 57:597-602, 1982

12. Lee MH, Kim HR, Seol HJ, Shin HJ: Neuroendoscopic biopsy of pediatric brain tumors with small ventricle. Childs Nerv Syst 30:1055-1060, 2014

13. Marinov M, Undjian S, Wetzka P: An evaluation of the surgical treatment of intracranial arachnoid cysts in children. Childs Nerv Syst 5:177-183, 1989

14. Moon KS, Lee JK, Kim JH, Kim SH: Spontaneous disappearance of a suprasellar arachnoid cyst: case report and review of the literature. Childs Nerv Syst 23:99-104, 2007

15. Naftel RP, Tubbs RS, Reed GT, Wellons JC III: Small ventricular access prior to rigid neuroendoscopy. J Neurosurg Pediatr 6:325-328, 2010

16. Oberbauer RW, Haase J, Pucher R: Arachnoid cysts in children: a European co-operative study. Childs Nerv Syst 8: 281-286, 1992

17. Ozek MM, Urgun K: Neuroendoscopic management of suprasellar arachnoid cysts. World Neurosurg 79 (2 Suppl):S19.e13-S19.e18, 2013

18. Pierre-Kahn A, Capelle L, Brauner R, Sainte-Rose C, Renier D, Rappaport R, et al: Presentation and management of suprasellar arachnoid cysts. Review of 20 cases. J Neurosurg 73:355-359, 1990

19. Pierre-Kahn A, Hanlo P, Sonigo P, Parisot D, McConnell RS: The contribution of prenatal diagnosis to the understanding of malformative intracranial cysts: state of the art. Childs Nerv Syst 16:619-626, 2000

20. Raffel C, McComb JG: To shunt or to fenestrate: which is the 
best surgical treatment for arachnoid cysts in pediatric patients? Neurosurgery 23:338-342, 1988

21. Rappaport ZH: Suprasellar arachnoid cysts: options in operative management. Acta Neurochir (Wien) 122:71-75, 1993

22. Rengachary SS, Watanabe I: Ultrastructure and pathogenesis of intracranial arachnoid cysts. J Neuropathol Exp Neurol 40:61-83, 1981

23. Sommer IE, Smit LM: Congenital supratentorial arachnoidal and giant cysts in children: a clinical study with arguments for a conservative approach. Childs Nerv Syst 13:8-12, 1997

24. Song JH, Kong DS, Seol HJ, Shin HJ: Transventricular biopsy of brain tumor without hydrocephalus using neuroendoscopy with navigation. J Korean Neurosurg Soc 47:415-419, 2010

25. Sood S, Schuhmann MU, Cakan N, Ham SD: Endoscopic fenestration and coagulation shrinkage of suprasellar arachnoid cysts. Technical note. J Neurosurg 102 (1 Suppl):127-133, 2005

26. Souweidane MM: Endoscopic surgery for intraventricular brain tumors in patients without hydrocephalus. Neurosurgery 62 (6 Suppl 3):1042-1048, 2008

27. Wang JC, Heier L, Souweidane MM: Advances in the endo- scopic management of suprasellar arachnoid cysts in children. J Neurosurg 100 (5 Suppl Pediatrics):418-426, 2004

\section{Disclosures}

The authors report no conflict of interest concerning the materials or methods used in this study or the findings specified in this paper.

\section{Author Contributions}

Conception and design: Gui. Acquisition of data: Wang, Gui, Bai, Li. Analysis and interpretation of data: Gui, Cao. Drafting the article: Gui. Critically revising the article: Gui. Reviewed submitted version of manuscript: Gui, Zhang. Statistical analysis: Gui, $\mathrm{Yu}$, Bai. Administrative/technical/material support: Wang, Gui, Zhang. Study supervision: Wang, Gui.

\section{Correspondence}

Xin-Sheng Wang, Department of Neurosurgery, Beijing Tiantan Hospital, Tiantan xili 6, Dongcheng District, Beijing 100050, China. email: xshwang@126.com. 